Article

\title{
Characteristics of the Water- and Alkali-Soluble Hemicelluloses Fractionated by Sequential Acidification and Graded-Ethanol from Sweet Maize Stems
}

\author{
Xiaopeng Peng ${ }^{1,2,3, *}$, Shuangxi Nie ${ }^{2}$, Xiaoping $\mathrm{Li}^{4}$, Xiong Huang ${ }^{1}$ and Quanzi $\mathrm{Li}^{1,3, *}$ \\ 1 State Key Laboratory of Tree Genetics and Breeding, Chinese Academy of Forestry, Beijing 100091, China; \\ huangxiong0839@163.com \\ 2 Guangxi Key Laboratory of Clean Pulp \& Papermaking and Pollution Control, Nanning 530004, China; \\ cppkl@gxu.edu.cn \\ 3 Research Institute of Forestry, Chinese Academy of Forestry, Beijing 100091, China \\ 4 Jiangsu Key Laboratory for Poplar Germplasm Innovation and Variety Improvement, \\ Nanjing Forestry University, Nanjing 210037, China; xpli@njfu.edu.cn \\ * Correspondence: xp@caf.ac.cn (X.P.); liqz@caf.ac.cn (Q.L.)
}

Academic Editor: Christophe Len Received: 3 December 2018; Accepted: 3 January 2019; Published: 8 January 2019

\begin{abstract}
Sweet maize stems were treated with hot water and potassium hydroxide to fractionate hemicellulosic polymers. The results showed that the water-soluble hemicelluloses were mainly composed of glucose $(27.83 \%)$, xylose $(27.32 \%)$, and galactose $(16.81 \%)$. In comparison, alkali-soluble hemicelluloses fractionated by acidification and a graded ethanol solution $(10 \%, 20 \%, 35 \%, 50 \%$, $65 \%$, and $80 \%$ ) were mainly composed of xylose (69.73 to $88.62 \%$ ) and arabinose (5.41 to $16.20 \%$ ). More highly branched hemicelluloses tended to be precipitated in a higher concentration of ethanol solution, as revealed by the decreasing xylose to arabinose ratio from 16.43 to 4.21 . Structural characterizations indicated that alkali-soluble hemicelluloses fractionated from sweet maize stems were mainly arabinoxylans. The results provided fundamental information on hemicelluloses composition and structure and their potential utilization in the fields of biofuels, biochemicals, and biomaterials.
\end{abstract}

Keywords: sweet maize stems; hemicelluloses; structural features; graded ethanol precipitation; fractionation

\section{Introduction}

Since excessive consumption of fossil fuels has caused increasing energy and environmental issues, the utilization of renewable, abundant, and inexpensive non-food lignocellulosic biomass is thought to be an effective way to relieve these problems [1]. Lignocellulose is mainly comprised of cellulose $(38-50 \%)$, hemicelluloses $(23-32 \%)$ and lignin $(15-25 \%)$, as well as small amounts of extractives and ash [2]. These components are strongly intermeshed and bonded through non-covalent forces and covalent cross-linkages, forming a lignocellulosic matrix. Hemicellulosic polymer can be converted into chemicals, such as xylitol, lactic acid, furfural, or erythritol [3]. They can also be used as intermediates for hemicellulose-based materials in hydrogels, film, pharmaceuticals, coatings, or papermaking $[4,5]$.

Hemicelluloses are composed of various pentose and hexose units, which are arranged in different proportions and substituents [6,7]. Hemicelluloses are branched heteropolymers with a degree of polymerization around 80 to 200 [8]. The content and chemical structure of hemicelluloses can 
vary within different biomass types and even in the same plant $[9,10]$. However, hemicelluloses are usually closely associated with other cell wall components, such as cellulose, lignin, and proteins. The utilization of hemicelluloses is based on their effective fractionation from plant cell walls. Many techniques, including alkali and acid extractions, steam explosion, and hot water extraction, are used to fractionate hemicelluloses from lignocellulose [9]. In these techniques, alkali extraction is well known to disrupt the cell walls and cleave the bonds between hemicelluloses and other components, resulting in the liberation of hemicelluloses in aqueous media [11,12]. Hemicelluloses in alkaline solvent can be separated using acidification precipitation, ethanol precipitation, membrane fractionation, or chromatograph fractionation [9,13-15]. Among these methods, both acidification and ethanol precipitation are the most commonly used to separate hemicelluloses from aqueous solvents, because they are both easily conducted and highly efficient. However, separation conditions may affect the composition and yield of hemicelluloses. To our knowledge, the composition, structure, and yield of hemicelluloses precipitated by acidification and graded ethanol solvents from sweet maize have rarely been studied.

In the present study, the composition, structure, and yield of alkali-soluble hemicelluloses from sweet maize stems precipitated by acidification and graded ethanol solvents $(10 \%, 20 \%, 35 \%, 50 \%$, $65 \%$, and $80 \%$ ) were comparatively analyzed. The hemicellulosic fractions were characterized by a high-performance anion exchange chromatography (HPAEC), gel permeation chromatography (GPC), and Fourier Transform Infrared (FT-IR) together with ${ }^{1} \mathrm{H}$ and ${ }^{13} \mathrm{C}$ NMR spectroscopies.

\section{Materials and Methods}

\subsection{Materials}

Sweet maize stems were obtained from the State Key Laboratory of Tree Genetics and Breeding, Research Institute of Forestry, Chinese Academy of Forestry, China. Air-dried stems were ground and selected to be within the 40 to 80 mesh for subsequent experiments. After drying in an oven at $60{ }^{\circ} \mathrm{C}$ for $12 \mathrm{~h}$, the stems were extracted with toluene/ethanol $(2: 1, v / v)$ in a Soxhlet apparatus for $6 \mathrm{~h}$ to remove wax and dried at $60^{\circ} \mathrm{C}$ for $12 \mathrm{~h}$ before use. The chemical composition (weight $\%$ ) was determined to be $38.1 \%$ cellulose, $28.0 \%$ hemicelluloses, and $15.0 \%$ acid-insoluble lignin, according to the National Renewable Energy Laboratory (NREL) standard analytical procedure. The derivations of these values from their respective means were all $<6 \%$. All chemicals were of analytical or reagent grade and used directly without further purification.

\subsection{Extraction of Hemicelluloses}

The dewaxed stems $(15.00 \mathrm{~g})$ were firstly extracted with distilled water at $80{ }^{\circ} \mathrm{C}$ for $2 \mathrm{~h}$ with a solid to liquid ratio of 1:25 g/L. The water-extractable solution was concentrated to about $30 \mathrm{~mL}$ and then poured into $90 \mathrm{~mL}$ of $95 \%$ ethanol while vigorously stirring. The precipitate was centrifuged, freeze-dried, and labeled as $\mathrm{H}_{\mathrm{H} 2 \mathrm{O}}$. Subsequently, the water-extracted residue was dried at $60^{\circ} \mathrm{C}$ for $12 \mathrm{~h}$ and delignified using $\mathrm{NaClO}_{2}$ at $\mathrm{pH} 3.6$ to 4.0 and adjusted with acetic acid (HOAc) at $75^{\circ} \mathrm{C}$ for 2 $\mathrm{h}$. The solid residue, known as holocellulose, was filtered with a nylon cloth, washed with distilled water thoroughly, and further dried in an oven at $60{ }^{\circ} \mathrm{C}$ for $16 \mathrm{~h}$. Then, the holocelluloses was extracted with $10 \% \mathrm{KOH}$ at $25^{\circ} \mathrm{C}$ for $16 \mathrm{~h}$ with a solid to liquid ratio of $1: 25 \mathrm{~g} / \mathrm{L}$. The hemicellulosic fraction (Ha) was precipitated by neutralizing the filtrate with HOAc to $\mathrm{pH} 5.5$ to 6.0. Next, the filtrate was concentrated under reduced pressure, and pure ethanol was added to the filtrate with continuous stirring to a final concentration of $10 \%(v / v)$. The precipitated hemicellulosic polymer was recovered by centrifugation and marked as $\mathrm{H}_{10}$. The supernatant was further sequentially fractionated by graded precipitations in ethanol concentrations of $20 \%, 35 \%, 50 \%, 65 \%$, and $80 \%$, leading to hemicellulosic fractions $\mathrm{H}_{20}, \mathrm{H}_{35}, \mathrm{H}_{50}, \mathrm{H}_{65}$, and $\mathrm{H}_{80}$, respectively. All the hemicellulosic fractions were dialyzed against distilled water and then freeze-dried. Three replicates were carried out for each procedure. 
The scheme for the isolation and precipitation of hemicelluloses from sweet maize stems used in this work is shown in Figure 1.

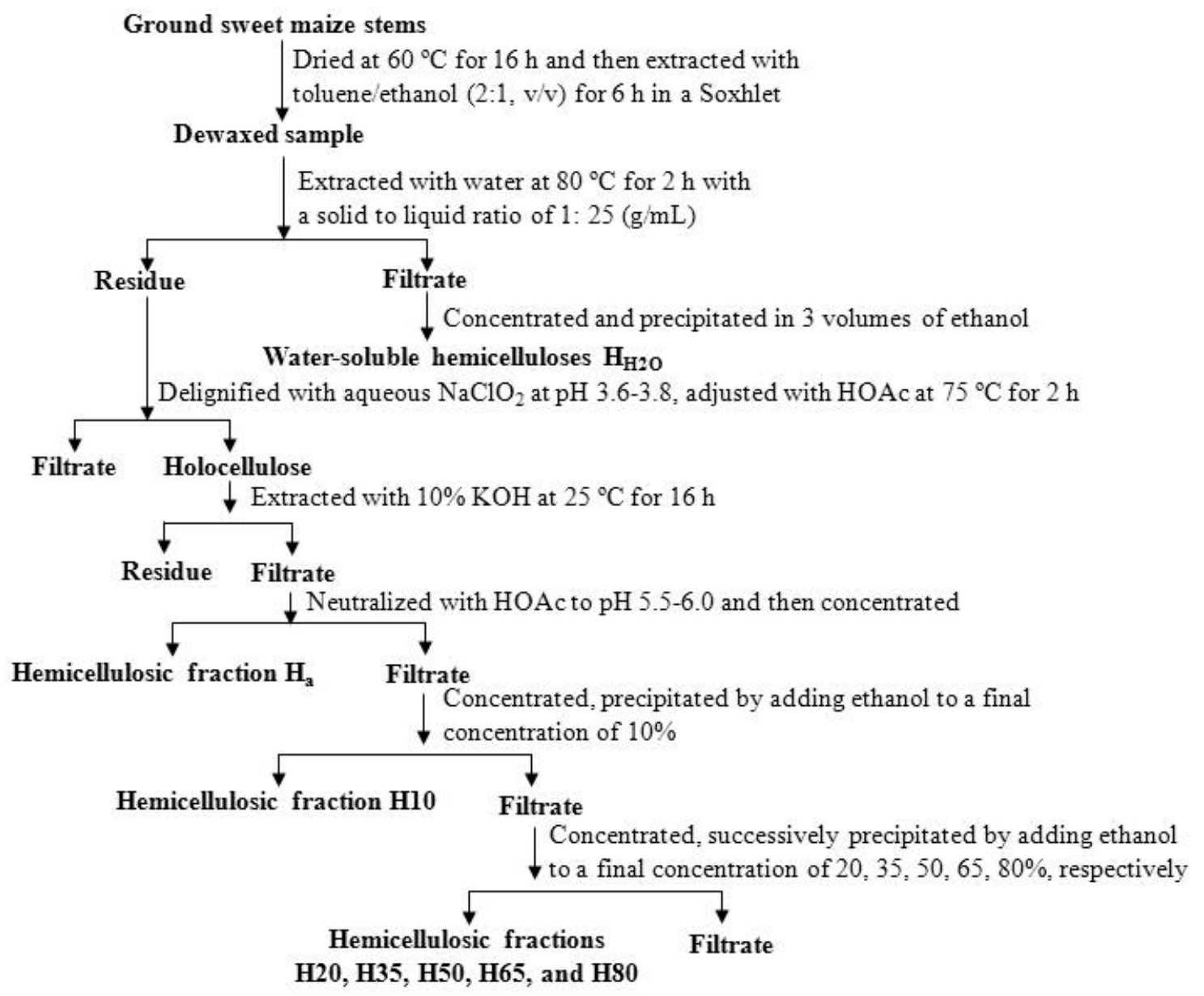

Figure 1. Scheme of hemicellulose fractionation from sweet maize stems.

\subsection{Structural Characterization}

The neutral sugars and uronic acids of the eight hemicellulosic fractions were examined by high-performance anion exchange chromatography (HPAEC) (Dionex, Sunnyvale, CA, USA). The hemicelluloses (5 mg) were hydrolyzed by $4 \mathrm{~mL}$ of $6 \%$ sulphuric acid at $105{ }^{\circ} \mathrm{C}$ for $2.5 \mathrm{~h}$, and then the hydrolysate was diluted 50-fold with ultrapure water and injected into an HPAEC system. The molecular weights and molecular weight distributions were determined by gel permeation chromatograph (GPC) (Dionex, Sunnyvale, CA, USA) according to previous work [16].

The FT-IR spectra of the hemicellulosic fractions were recorded on a Bruker spectrophotometer (Bruker BioSpin AG, Fällanden, Switzerland) in the range of 4000 to $400 \mathrm{~cm}^{-1}$ with a resolution of $4 \mathrm{~cm}^{-1}$. A KBr disc containing 1\% finely ground hemicelluloses was used for measurement. The solution-state ${ }^{1} \mathrm{H}$ and ${ }^{13} \mathrm{C}$ NMR spectra were recorded on a Bruker AV III $400 \mathrm{MHz}$ spectrometer operating in the FT mode at $100.6 \mathrm{MHz}$. The purified hemicelluloses $\left(15 \mathrm{mg}\right.$ for ${ }^{1} \mathrm{H} \mathrm{NMR}$ and $80 \mathrm{mg}$ for ${ }^{13} \mathrm{C}$ NMR) were dissolved in $1 \mathrm{~mL}$ of $\mathrm{D}_{2} \mathrm{O}$, and then the resonance spectra were obtained. For ${ }^{1} \mathrm{H}$ NMR spectra, the acquisition and relaxation times were 3.9 and $1.0 \mathrm{~s}$, respectively. For ${ }^{13} \mathrm{C}$ NMR spectra, the spectra were recorded at $25^{\circ} \mathrm{C}$ after 30,000 scans. A $30^{\circ}$ pulse flipping angle, $9.2 \mu$ s pulse width, $1.36 \mathrm{~s}$ acquisition time, and $1.89 \mathrm{~s}$ relaxation delay time were used. The spectral widths were 2200 and $15,400 \mathrm{~Hz}$ for the ${ }^{1} \mathrm{H}$ and ${ }^{13} \mathrm{C}$ dimensions, respectively. 


\section{Results and Discussion}

\subsection{Yield and Chemical Composition}

The yield and composition of hemicelluloses varied depending on the isolation and precipitation methods. The water-soluble hemicellulosic fraction $\mathrm{H}_{\mathrm{H} 2 \mathrm{O}}$ was precipitated by $95 \%$ ethanol with a yield of $3.3 \%$ of the dewaxed samples, corresponding to $11.8 \%$ of the original hemicelluloses. Most hemicelluloses are intermeshed and bonded through covalent cross-linkages with lignin [17]. The fractionation of hemicelluloses from the cell wall is strongly restricted by the lignin network and lignin-carbohydrate complexes. Therefore, the sweet maize stems were delignified with acidified sodium chlorite solution and then extracted with $10 \% \mathrm{KOH}$ to recover most of the hemicelluloses. After neutralization of the $\mathrm{KOH}$-soluble liquid and concentration, Ha was precipitated from solution with a yield of $8.3 \%$ of the dewaxed samples. Then the solution was further precipitated by $10 \%, 20 \%$, $35 \%, 50 \%, 65 \%$, and $80 \%$ ethanol, resulting in six hemicellulosic fractions labeled as $\mathrm{H}_{10}, \mathrm{H}_{20}, \mathrm{H}_{35}$, $\mathrm{H}_{50}, \mathrm{H}_{65}$, and $\mathrm{H}_{80}$, respectively. Result showed that the yields of $\mathrm{H}_{10}, \mathrm{H}_{20}, \mathrm{H}_{35}, \mathrm{H}_{50}, \mathrm{H}_{65}$, and $\mathrm{H}_{80}$ were $3.1,1.4 \%, 0.4 \%, 2.3 \%, 1.3 \%$, and $0.4 \%$ of the dewaxed stems, corresponding to $11.1 \%, 5.0 \%$, $1.4 \%, 8.2 \%, 4.6 \%$, and $1.4 \%$ of the original hemicelluloses, respectively. The result showed that most hemicelluloses were extracted with alkali solution from the delignified material since hydroxyl ions caused swelling of cellulose, disruption of intermolecular hydrogen bonds between hemicelluloses and cellulose, and hydrolysis of ester bonds [18,19]. A total yield of $73.2 \%$ of the original hemicelluloses was fractionated from the sweet maize stems. Obviously, most hemicelluloses were obtained by $\mathrm{KOH}$ extraction, while fewer hemicelluloses were obtained by hot water extraction, suggesting that the alkali treatment was an effective method for the fractionation of hemicelluloses from sweet maize stems.

The contents of neutral sugars and uronic acids in these isolated hemicelluloses are shown in Table 1. As can be seen, $\mathrm{H}_{\mathrm{H} 2 \mathrm{O}}$ contained an abundance of glucose (27.83\%), xylose (27.32\%), galactose $(16.81 \%)$, mannose (13.94\%), and arabinose (12.65\%) as well as small amounts of rhamnose (1.72\%). The high content of glucose was ascribed to the existence of starch and/or $\alpha$-glucan in the plant cell walls of sweet maize stems. However, in all the alkali-soluble hemicellulosic fractions, xylose was the dominant sugar, and arabinose appeared as the second major sugar. Glucose, galactose, rhamnose, mannose, and uronic acids were observed in these hemicellulosic fractions in minor amounts. The result suggested that the hemicelluloses isolated from the alkali solution were mainly arabinoxylans. Interestingly, the content of xylose in the hemicellulosic fractions $\mathrm{H}_{10}$ to $\mathrm{H}_{80}$ gradually decreased from $88.62 \%$ to $69.73 \%$ as the concentration of ethanol increased from $10 \%$ to $80 \%$, while the content of arabinose gradually increased from $5.41 \%$ to $16.20 \%$. Furthermore, the ratio of xylose to arabinose decreased from 16.43 to 4.21 , indicating that the increase in ethanol concentrations led to the precipitation of less linear hemicelluloses. That is, hemicelluloses rich in backbone structure could be precipitated at low ethanol concentrations, while with increasing ethanol concentrations, hemicelluloses with more side chains and complex structures were obtained.

Table 1. Contents of neutral sugars and uronic acids (relative $\%, W / W$ ) in the isolated hemicellulosic fractions.

\begin{tabular}{ccccccccc}
\hline Sugars (\%) & $\mathbf{H}_{\mathbf{H}_{\mathbf{2}} \mathbf{O}}$ & $\mathbf{H}_{\mathbf{a}}$ & $\mathbf{H}_{\mathbf{1 0}}$ & $\mathbf{H}_{\mathbf{2 0}}$ & $\mathbf{H}_{\mathbf{3 5}}$ & $\mathbf{H}_{\mathbf{5 0}}$ & $\mathbf{H}_{\mathbf{6 5}}$ & $\mathbf{H}_{\mathbf{8 0}}$ \\
\hline Rhamnose & 1.72 & $\mathrm{ND}$ & $\mathrm{ND}$ & $\mathrm{ND}$ & $\mathrm{ND}$ & 0.25 & $\mathrm{ND}$ & 0.11 \\
Arabinose & 12.65 & 4.21 & 5.41 & 5.57 & 6.11 & 7.65 & 9.11 & 16.20 \\
Galactose & 16.81 & $\mathrm{ND}$ & 0.42 & 0.86 & 1.21 & 0.87 & 1.56 & 4.18 \\
Glucose & 27.83 & 0.39 & 0.94 & 1.04 & 2.13 & 1.67 & 3.55 & 3.13 \\
Mannose & 13.94 & $\mathrm{ND}$ & $\mathrm{ND}$ & $\mathrm{ND}$ & $\mathrm{ND}$ & $\mathrm{ND}$ & $\mathrm{ND}$ & 0.25 \\
Xylose & 27.32 & 90.10 & 88.62 & 85.73 & 83.22 & 82.14 & 80.23 & 69.73 \\
Uronic acids & $\mathrm{ND}^{\mathrm{a}}$ & 5.30 & 4.70 & 6.80 & 7.33 & 7.67 & 5.55 & 6.49 \\
Xyl/Ara ${ }^{\mathrm{b}}$ & 2.17 & 21.40 & 16.43 & 15.39 & 13.62 & 10.74 & 8.81 & 4.21 \\
\hline \multicolumn{7}{c}{ (1) nd not detectable. ${ }^{\mathrm{b}}$ Represent xylose to arabinose ratio. }
\end{tabular}




\subsection{Molecular Weight}

To investigate the degree of degradation of these hemicelluloses during extraction, the molecular weights of all the hemicellulosic fractions were determined. Table 2 shows their weight average $\left(M_{w}\right)$ and the number of average molecular weights as well as polydispersity $\left(M_{w} / M_{n}\right)$. It was found that the $M_{w}$ value was $40,430 \mathrm{~g} / \mathrm{mol}$ for $\mathrm{H}_{\mathrm{H} 2 \mathrm{O}}$ and 43,490 to $110,400 \mathrm{~g} / \mathrm{mol}$ for $\mathrm{H}_{\mathrm{a}}$ and $\mathrm{H}_{10}$ through $\mathrm{H}_{80}$, suggesting that the hemicelluloses extracted with hot water had a lower $M_{w}$ than those extracted with alkali solution from the delignified material. This phenomenon indicated that the hot water treatment only dissolved low molecular hemicelluloses (i.e., galactoarabinoxylans, pectic substances, and $\alpha$-glucan) [20], while the alkali treatment of holocellulose from sweet maize stems released highly molecular hemicelluloses; the $M_{w}$ values of hemicellulosic polymers varied depending on the precipitating ethanol concentrations. In all the alkali-soluble hemicelluloses, Ha precipitated by acidification had a low $M_{w}$ as compared with the hemicelluloses precipitated by ethanol. An increase in ethanol concentration from $10 \%$ to $65 \%$ led to the rise in the $M_{w}$ value from 61,170 to $110,400 \mathrm{~g} / \mathrm{mol}$, whereas a further increase in ethanol concentration to $80 \%$ resulted in a decrease in $M_{w}$ to $73,690 \mathrm{~g} / \mathrm{mol}$. The result indicated that the ethanol concentrations of $50 \%$ and $65 \%$ favored the precipitation of the hemicelluloses with higher molecular weights, whereas, with the further increase of the ethanol concentration, the molecular weight of the precipitated hemicelluloses decreased. Furthermore, it was found that as compared with the water-soluble hemicelluloses $\left(M_{w} / M_{n}=3.2\right)$, the alkali-soluble hemicelluloses had relatively lower polydispersities $\left(M_{w} / M_{n}=2.0\right.$ to 3.0). It is probable that the alkali-soluble hemicelluloses had a homogenous structure, mainly xylan-based hemicelluloses, while the water-soluble hemicellulosic polymer was a mixture of hemicelluloses, pectic substances, and $\alpha$-glucan as revealed by sugar analysis.

Table 2. Weight-average $\left(M_{w}\right)$ and number-average $\left(M_{n}\right)$ molecular weights and polydispersity $\left(M_{w} / M_{n}\right)$ of the hemicellulosic fractions isolated from sweet maize stems.

\begin{tabular}{ccccccccc}
\hline & $\mathbf{H}_{\mathbf{H}_{\mathbf{2}} \mathbf{O}}$ & $\mathbf{H}_{\mathbf{a}}$ & $\mathbf{H}_{\mathbf{1 0}}$ & $\mathbf{H}_{\mathbf{2 0}}$ & $\mathbf{H}_{\mathbf{3 5}}$ & $\mathbf{H}_{\mathbf{5 0}}$ & $\mathbf{H}_{\mathbf{6 5}}$ & $\mathbf{H}_{\mathbf{8 0}}$ \\
\hline$M_{w}$ & 40,430 & 43,490 & 61,170 & 72,940 & 76,040 & 99,520 & 110,400 & 73,690 \\
$M_{n}$ & 12,630 & 18,910 & 26,360 & 24,310 & 34,420 & 36,860 & 55,200 & 35,090 \\
$M_{w} / M_{n}$ & 3.2 & 2.3 & 2.7 & 3.0 & 2.5 & 2.7 & 2.0 & 2.1 \\
\hline
\end{tabular}

\subsection{FT-IR Spectra Analysis}

The FT-IR spectra of all the hemicellulosic fractions obtained are shown in Figure 2. No significant difference in the main absorptions was observed among the alkali-soluble hemicelluloses, suggesting a similar chemical structure of the hemicellulosic polymers. The bands at 1465, 1414, 1385, 1327, 1255, $1168,1040,984$, and $902 \mathrm{~cm}^{-1}$ are characteristic peaks of hemicelluloses [21,22]. A predominant absorption at $1040 \mathrm{~cm}^{-1}$ is due to the $\mathrm{C}-\mathrm{O}-\mathrm{C}$ stretching of glycosidic linkages of xylans $[9,23]$. The presence of arabinose as side chains on xylans is indicated by the absorption at $1168 \mathrm{~cm}^{-1}$ [24]. A low intensity of the signal at $984 \mathrm{~cm}^{-1}$ also indicated the presence of arabinose units, and it has been reported that arabinose was attached at the $\mathrm{C}-3$ position of the xylopyranosyl constituents [24]. A characteristic band at $902 \mathrm{~cm}^{-1}$, corresponding to the $\mathrm{C} 1$ group frequency or ring frequency, is assigned to the $\beta-(1,4)$-glycosidic linkages in the hemicellulosic polymers [25]. This band was observed in all the alkali-soluble hemicelluloses but not observed in the water-soluble hemicelluloses, which was probably due to the fact that the relative content of xylose in the alkali-soluble hemicelluloses was remarkably higher than that in $\mathrm{H}_{\mathrm{H} 2 \mathrm{O}}$. In addition to the bands at $1168,1040,984$, and $902 \mathrm{~cm}^{-1}$, the absorptions at 1465 and $1414 \mathrm{~cm}^{-1}$ represent symmetric stretching vibrations of glucuronic acid groups and those at 1385 and $1255,1327 \mathrm{~cm}^{-1}$ represent $\mathrm{C}-\mathrm{H}$ stretching and $\mathrm{O}-\mathrm{H}$ or $\mathrm{C}-\mathrm{O}$ bending vibrations. 


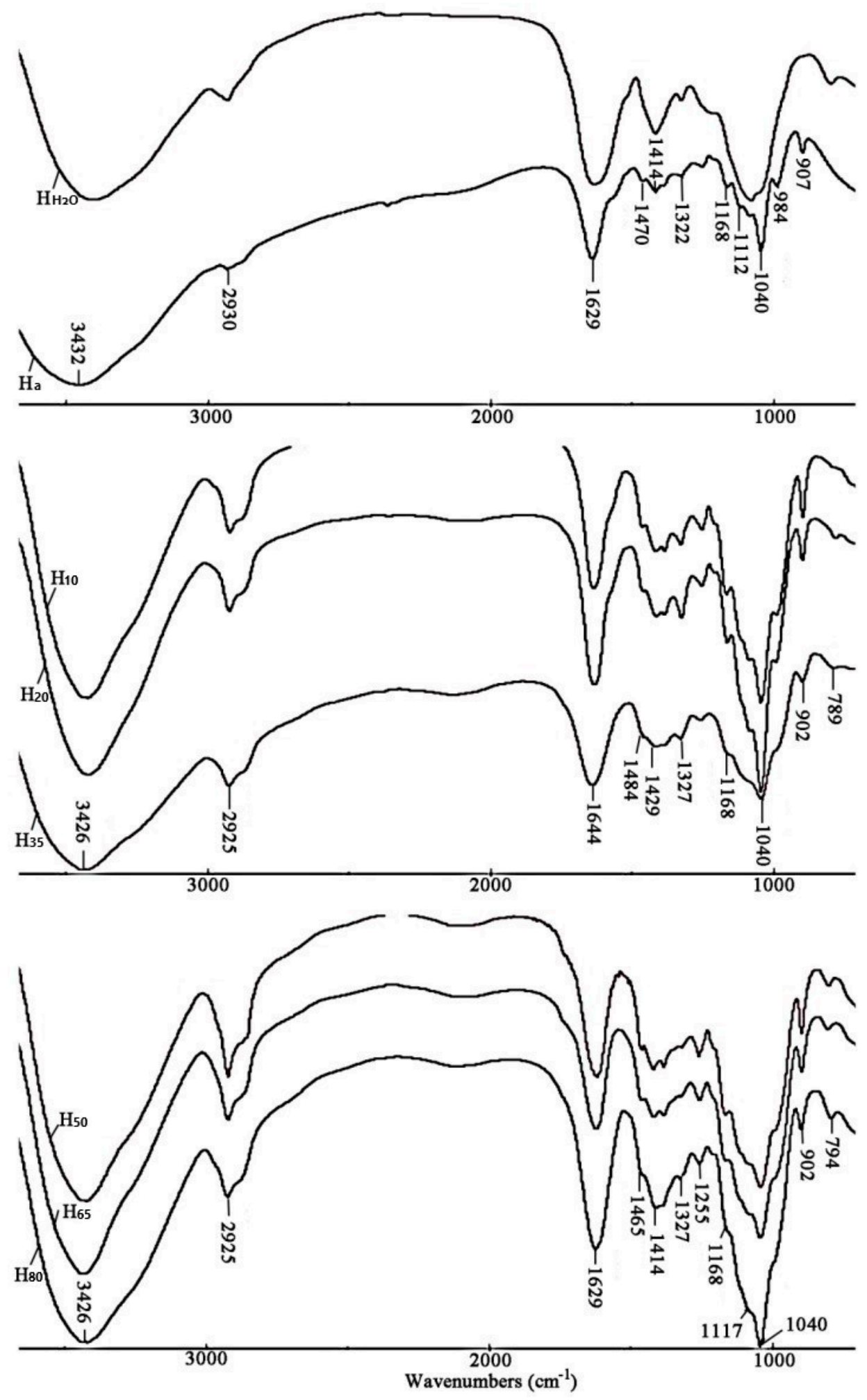

Figure 2. FT-IR spectra of the hemicellulosic fractions.

\section{4. ${ }^{1} \mathrm{H}$ and ${ }^{13} \mathrm{C}$ NMR Spectra Analysis}

To further elucidate the structural information of the hemicellulosic polymers, the hemicellulosic fractions $\mathrm{H}_{65}$ were investigated by using the ${ }^{1} \mathrm{H}$ and ${ }^{13} \mathrm{C}$ NMR spectra (Figure 3). For ${ }^{1} \mathrm{H}$ NMR spectra, the relevant signals occurred in two regions: the anomeric region (5.60 to $4.90 \mathrm{ppm}$ for $\alpha$ anomers and 4.90 to $4.30 \mathrm{ppm}$ for $\beta$ anomers) and the ring proton region (4.50 to $3.00 \mathrm{ppm})[26,27]$. 
It was found that the intensity of $\beta$ anomers was higher than that of $\alpha$ anomers, confirming that the xylose units were linked $\beta$-glycosidically, which was in accordance with the presence of absorption at $902 \mathrm{~cm}^{-1}$ in the FT-IR spectra. The six main signals at $4.4(\mathrm{H}-1), 4.1(\mathrm{H}-5 \mathrm{eq}), 3.8(\mathrm{H}-4), 3.5(\mathrm{H}-3)$, $3.4(\mathrm{H}-5 \mathrm{ax})$, and $3.3(\mathrm{H}-2) \mathrm{ppm}$ are assigned to non-substituted backbone of $\beta-\mathrm{D}-\mathrm{xylopyranosyl}$ units [23]. Additionally, a small signal at $5.3 \mathrm{ppm}$ was related to anomeric protons of terminal $\alpha$-D-arabinofuranosyl. For ${ }^{13} \mathrm{C}$ NMR spectra, $\beta-(1,4)$-linked xylopyranosyl units are characterized by the five main signals at 102.0, 75.9, 74.5, 73.0, and $63.2 \mathrm{ppm}$, which corresponded to the $\mathrm{C}-1, \mathrm{C}-4$, $\mathrm{C}-3, \mathrm{C}-2$, and $\mathrm{C}-5$ positions, respectively [6]. The signals at 109.3, 86.3, 80.1, 78.3, and $61.6 \mathrm{ppm}$ are indicative of $\mathrm{C}-1, \mathrm{C}-4, \mathrm{C}-2, \mathrm{C}-3$, and $\mathrm{C}-5$ of $\alpha-\mathrm{L}$-arabinofuranosyl units linked to $\beta-\mathrm{D}-\mathrm{xylans}$, respectively. Moreover, some small signals at $97.5,82.5,72.2$, and $59.6 \mathrm{ppm}$ corresponding to $C-1$, $\mathrm{C}-4, \mathrm{C}-5$, and $\mathrm{OCH}_{3}$ of the 4-O-methyl-D-glucoronic acids, respectively, were also observed [28]. Therefore, based on the results of sugar analysis and FT-IR and NMR spectra it could be concluded that the alkali-soluble hemicelluloses extracted from the holocellulose of sweet maize stems were mainly composed of arabinoxylans.
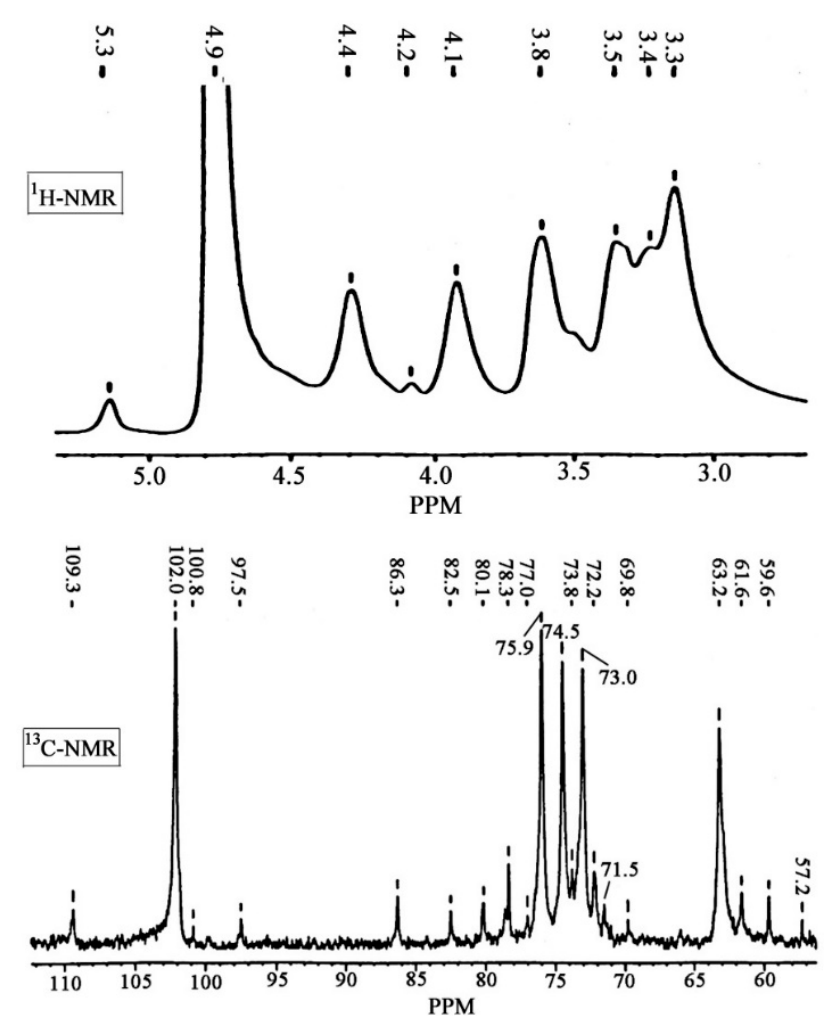

Figure $3 .{ }^{1} \mathrm{H}$ and ${ }^{13} \mathrm{C}$ NMR spectra of the hemicelluloses $\mathrm{H}_{65}$ obtained from sweet maize stems.

\section{Conclusions}

The hemicellulosic polymer from sweet maize stems was firstly fractionated with water and alkaline treatment and then fully characterized by wet chemical and spectral technologies. The water-soluble hemicelluloses were rich in glucose, xylose, and galactose with a relatively low molecular weight. In comparison, the alkali-soluble hemicelluloses were rich in xylose and arabinose with high molecular weight and polydispersity. Although the core of hemicellulosic biomacromolecule could be maintained and isolated under alkaline conditions, the polymer with less branches was easier to be precipitated at a low ethanol concentration. The hemicellulosic fraction with a more complex structure could be isolated with increasing ethanol concentration. The effective strategy for the fractionation and basic understanding of hemicelluloses hopefully provides new opportunities for future applications. 
Author Contributions: Data curation, X.P.; formal analysis, S.N.; investigation, X.L.; methodology, X.P.; project administration, Q.L.; writing—original draft, X.P.; writing—review and editing, X.P.

Funding: This work was partially supported by the Fundamental Research Funds for the Central Non-profit Research Institution of Chinese Academy of Forestry (CAFYBB2018MA006), the Open Fund of Guangxi Key Laboratory of Clean Pulp \& Papermaking and Pollution Control, Nanning 530004, China (KF201722), the Open Fund of Jiangsu Key Laboratory for Poplar Germplasm Innovation and Variety Improvement (2018JSPD002), and the National Natural Science Foundation of China (31700578).

Conflicts of Interest: The authors declare no conflict of interest.

\section{References}

1. Jiménez-González, C.; Poechlauer, P.; Broxterman, Q.B.; Yang, B.S.; Am Ende, D.; Baird, J.; Bertsch, C.; Hannah, R.E.; Dell'Orco, P.; Noorman, H.; et al. Key green engineering research areas for sustainable manufacturing: A perspective from pharmaceutical and fine chemicals manufacturers. Org. Process Res. Dev. 2017, 15, 900-911. [CrossRef]

2. Ashwani, K. Assessment of different pretreatment technologies for efficient bioconversion of lignocellulose to ethanol. Front. Biosci. 2018, 10, 350-371. [CrossRef]

3. Li, X.; Guo, T.; Xia, Q.; Liu, X.; Wang, Y. One-pot catalytic transformation of lignocellulosic biomass into alkylcyclohexanes and polyols. ACS Sustain. Chem. Eng. 2018, 6, 4390-4399. [CrossRef]

4. Lindblad, M.S.; Ranucci, E.; Albertsson, A.C. Biodegradable polymers from renewable sources. New hemicellulose-based hydrogels. Macromol. Rapid Commun. 2001, 22, 962-967. [CrossRef]

5. Gröndahl, M.; Eriksson, L.; Gatenholm, P. Material properties of plasticized hardwood xylans for potential application as oxygen barrier films. Biomacromolecules 2004, 5, 1528-1535. [CrossRef]

6. Farhat, W.; Venditti, R.; Quick, A.; Taha, M.; Mignard, N.; Becquart, F.; Ayoub, A. Hemicellulose extraction and characterization for applications in paper coatings and adhesives. Ind. Crops Prod. 2017, 107, 370-377. [CrossRef]

7. Huang, H.J.; Ramaswamy, S.; Tschirner, U.W.; Ramarao, B.V. A review of separation technologies in current and future biorefineries. Sep. Purif. Technol. 2015, 62, 1-21. [CrossRef]

8. Bai, L.K.; Hu, H.R.; Xu, J.F. Influences of configuration and molecular weight of hemicelluloses on their paper-strengthening effects. Carbohydr. Polym. 2012, 88, 1258-1263. [CrossRef]

9. Peng, F.; Peng, P.; Xu, F.; Sun, R.C. Fractional purification and bioconversion of hemicelluloses. Biotechnol. Adv. 2012, 30, 879-903. [CrossRef]

10. Peng, X.P.; Bian, J.; Li, M.F.; Xiao, X.; Xia, X.L.; Yin, W.L.; Sun, R.C. Graded Ethanol Fractionation and Structural Characterization of Alkali-Extractable Hemicelluloses from Olea europaea L. BioResources 2013, 8, 1110-1123. [CrossRef]

11. Sorokina, K.N.; Samoylova, Y.V.; Piligaev, A.V.; Sivakumar, U.; Parmon, V.N. New methods for the one-pot processing of polysaccharide components (cellulose and hemicelluloses) of lignocellulose biomass into valuable products. Part 3: Products synthesized via the biotechnological conversion of poly- and monosaccharides of biomass. Catal. Ind. 2017, 9, 270-276. [CrossRef]

12. Cara, C.; Ruiz, E.; Ballesteros, I.; Negro, M.J.; Castro, E. Enhanced enzymatic hydrolysis of olive tree wood by steam explosion and alkaline peroxide delignification. Process Biochem. 2006, 41, 423-429. [CrossRef]

13. Schlesinger, R.; Götzinger, G.; Sixta, H.; Friedl, A.; Harasek, M. Evaluation of alkali resistant nanofiltration membranes for the separation of hemicellulose from concentrated alkaline process liquors. Desalination 2006, 192, 303-314. [CrossRef]

14. Subba Rao, M.; Muralikrishna, G. Hemicelluloses of ragi (Finger Millet, Eleusine coracana, Indaf-15): Isolation and purification of an alkali-extractable arabinoxylan from native and malted hemicellulose $\mathrm{B}$. J. Agric. Food. Chem. 2006, 54, 2342-2349. [CrossRef] [PubMed]

15. Cyran, M.R.; Saulnier, L. Association and structural diversity of hemicelluloses in the cell walls of rye outer layers: Comparison between two ryes with opposite breadmaking quality. J. Agric. Food. Chem. 2007, 55, 2329-2341. [CrossRef] [PubMed]

16. Sun, S.N.; Cao, X.F.; Xu, F.; Sun, R.C.; Jones, G.L.; Baird, M. Structure and thermal property of alkaline hemicelluloses from steam exploded Phyllostachys pubescens. Carbohydr. Polym. 2014, 101, 1191-1197. [CrossRef] [PubMed] 
17. Pérez, J.; Munoz-Dorado, J.; de la Rubia, T.; Martinez, J. Biodegradation and biological treatments of cellulose, hemicellulose and lignin: An overview. Int. Microbiol. 2002, 5, 53-63. [CrossRef] [PubMed]

18. Bergmans, M.; Beldman, G.; Gruppen, H.; Voragen, A. Optimisation of the selective extraction of (glucurono) arabinoxylans from wheat bran: Use of barium and calcium hydroxide solution at elevated temperatures. J. Cereal Sci. 1996, 23, 235-245. [CrossRef]

19. Izdorczyk, M.; Macri, L.; MacGregor, A. Structural and physicochemical properties of barley non-starch polysaccharides-II. Alkali-extractable $\beta$-glucans and arabinoxylans. Carbohydr. Polym. 1998, 35, 259-269. [CrossRef]

20. Xu, F.; Sun, J.; Geng, Z.; Liu, C.; Ren, J.; Sun, R.; Fowler, P.; Baird, M. Comparative study of water-soluble and alkali-soluble hemicelluloses from perennial ryegrass leaves (Lolium peree). Carbohydr. Polym. 2007, 67, 56-65. [CrossRef]

21. Kačuráková, M.; Belton, P.S.; Wilson, R.H.; Hirsch, J.; Ebringerová, A. Hydration properties of xylan-type structures: An FTIR study of xylooligosaccharides. J. Sci. Food Agric. 1998, 77, 38-44. [CrossRef]

22. Saeed, F.; Pasha, I.; Anjum, F.M.; Sultan, M.T. Arabinoxylans and arabinogalactans: A comprehensive treatise. Crit. Rev. Food Sci. Nutr. 2011, 51, 467-476. [CrossRef] [PubMed]

23. Moine, C.; Krausz, P.; Chaleix, V.; Sainte-Catherine, O.; Kraemer, M.; Gloaguen, V. Structural characterization and cytotoxic properties of a 4-O-methylglucuronoxylan from Castanea sativa. J. Nat. Prod. 2007, 70, 60-66. [CrossRef]

24. Ebringerova, A.; Hromadkova, Z.; Alfoldi, J.; Berth, G. Structure and solution properties of corn cob heteroxylans. Carbohydr. Polym. 1992, 19, 99-105. [CrossRef]

25. Kalam Azad, M.A.; Wang, F.; Kim, H.R. Identification of a novel sugar compound from korean pine seeds. Food Sci. Biotechnol. 2015, 24, 2011-2015. [CrossRef]

26. Li, X.; Xiong, F.; Liu, Y.; Liu, F.; Hao, Z.; Chen, H. Total fractionation and characterization of the water-soluble polysaccharides isolated from enteromorpha intestinalis. Int. J. Biol. Macromol. 2018, 111, 319-325. [CrossRef]

27. Hoffmann, R.; Kamerling, J.; Vliegenthart, J. Structural feature of water-soluble arabinoxylans from the endosperm of wheat. Carbohydr. Res. 1992, 226, 303-311. [CrossRef]

28. Chaikumpollert, O.; Methacanon, P.; Suchiva, K. Structural elucidation of hemicelluloses from Vetiver grass. Carbohydr. Polym. 2004, 57, 191-196. [CrossRef]

Sample Availability: Samples of the compounds are not available from the authors.

(C) 2019 by the authors. Licensee MDPI, Basel, Switzerland. This article is an open access article distributed under the terms and conditions of the Creative Commons Attribution (CC BY) license (http://creativecommons.org/licenses/by/4.0/). 